\title{
New considerations on pupillary block mechanism
}

\author{
Novas considerações sobre o mecanismo do bloqueio pupilar
}

\author{
SebastiãoCronemberger ${ }^{1}$ \\ Nassim Calixto ${ }^{2}$ \\ André Oliveira de Andrade $^{3}$ \\ Rafael Vidal Mérula ${ }^{4}$
}

\begin{tabular}{|l|}
\hline ABSTRACT \\
\hline Purpose: To study the mechanisms of pupillary block in eyes with \\
occludable angle by ultrasound biomicroscopy. Methods: Initially, a \\
pilot study of 13 eyes with acute primary angle-closure without me- \\
dication was executed. Ultrasound biomicroscopy measurements of \\
the angle, posterior chamber depth and iris thickness were performed \\
in the temporal quadrant under light and dark conditions. Afterwards, \\
ultrasound biomicroscopy measurements of iris-lens contact distan- \\
ce and iris-lens angle in the temporal quadrant and central anterior \\
chamber depht were made in 32 eyes with acute primary angle-closure \\
or intermittent primary angle-closure without medication, under light \\
and dark conditions before and after laser peripheral iridectomy. Re- \\
sults: In the pilot study, a significant decrease in the angle as well as a \\
significant increase in the iris thickness occurred when comparing \\
light to dark conditions. Before and after laser peripheral iridectomy \\
(second study), significant differences were found in iris-lens contact \\
distance (P<0.001) and iris-lens angle (P<0.001) under light and dark \\
conditions. Also, significant differences were found in light and dark \\
conditions, beforelaserperipheral iridectomy,in iris-lens angle (P=0.005), \\
and after laser peripheral iridectomy, in iris-lens contact distance \\
(P<0.001). No significant change occurred with anterior chamber depth. \\
Conclusions: A decreased angle was correlated to an increase in iris \\
thickness. After laser peripheral iridectomy, acute primary angle-closure \\
or primary angle-closure eyes had an increased iris-lens contact distance \\
and a decreased iris-lens angle. The anterior chamber depth did not \\
change. These findings contradict the theory that pupillary block is the \\
mechanism of acute primary angle-closure.
\end{tabular}

Keywords: Glaucoma, angle-closure/ultrasonography; Microscopy/methods; Anterior chamber/ ultrasonography; Lens, crystalline/physiopathology; Iris/physiopathology

\section{INTRODUCTION}

The most accepted theory regarding the mechanism responsible for the development of acute primary angle-closure (APAC) is an increased resistance caused by relative pupillary block which prevents the aqueous humour from flowing through the pupil ${ }^{(1-2)}$. Eyes with angle-closure have important biometric differences from healthy eyes, such as: shorter corneal diameter, shallower anterior chamber, thicker lens, more anterior positioned lens, and shorter axial length ${ }^{(3)}$. In these eyes, a prophylactic treatment is available to avoid acute episodes. A laser peripheral iridectomy (LPI) flattens the convex iris ${ }^{(4-5)}$ and widens the angle ${ }^{(6)}$ relieving the pupillary block. However, this treatment is not complication free and does 
not prevent APAC crisis in some eyes. It must be indicated when potential benefits outweigh risks.

Ultrasound biomicroscopy (UBM) permits non-invasive examination of the ocular anterior segment at high resolution $(40 \mu \mathrm{m})^{(7)}$. Its efficacy has been demonstrated in relation to the mechanism of angle-closure in eyes with primary angle-closure glaucoma $(\mathrm{PACG})^{(8)}$, and the morphologic changes after $\mathrm{LPI}^{(6)}$. Other peculiarities, such as a more crowded anterior segment of the fellow APAC eyes in comparison to other narrow angle eyes have also benefited ${ }^{(9)}$. However, our knowledge about the pathophysiology of angle-closure is incomplete.

The aim of this paper is to report the results of an UBM study regarding pupillary block in eyes with occludable angle, under light and dark conditions, before and after LPI.

\section{METHODS}

This comparative case series study was approved by the Research Ethics Committee of the Federal University of Minas Gerais. Informed consent was obtained from all participants. Occludable angle subjects were recruited from the Glaucoma Service - São Geraldo Hospital.

Initially, a pilot study of 13 eyes from 13 patients with unilateral APAC without medication 48 hours before the UBM exam was executed. Afterwards, 32 eyes of 16 patients with APAC or intermittent primary angle-closure (IPAC) were assessed. APAC or IPAC cases were defined by the presence of at least two symptoms: ocular or periocular pain, nausea and/or vomiting, previous history of intermittent blurring of vision with haloes; and an intraocular pressure (IOP) higher than $28 \mathrm{mmHg}$ (Goldmann tonometry); the presence of three of the following signs: conjunctival injection, corneal epithelial edema, slowly reactive mid-dilated pupil, and a shallow anterior chamber; and presence of an appositional closed angle eye, verified by gonioscopy or UBM in darkness. Exclusion criteria were: posterior synechia; goniosynechia; impossibility to perform LPI due to corneal edema or corneal opacity; moderate or intense nuclear sclerosis defined as Lens Opacities Classification System (LOCS) II higher than grade 2 $(\mathrm{NC} 2, \mathrm{NO} 2)^{(10)}$; secondary glaucoma; plateau iris configuration (PIC) diagnosed by UBM exam described in a previous paper ${ }^{(9)}$ to confirm the diagnosis of PIC, (this exam revels anteriorly located ciliary processes which close the ciliary sulcus and provide structural support behind the peripheral iris); unresolved APAC crisis due to unresponsiveness to medical treatment and requiring surgical management (such as LPI or trabeculectomy); history of previous trauma, or surgical procedure (laser therapy or trabeculectomy) in one or both eyes; causes of angle-closure other than relative pupillary block.

APAC patients had medical therapy to reduce the IOP. This treatment comprised mannitol, given intravenously; acetazolamide, given orally; topical pilocarpine, timolol, and dexamethasone. More than 60 hours after the acute attack was controlled by IOP reduction providing corneal clarity and ab- sence of symptoms, the patients were submitted to clinical and UBM examination without medication. Clinical examination consisted of anamnesis, corrected visual acuity (decimal scale), biomicroscopy, gonioscopy and cup/disc (C/D) ratio evaluation. One of the authors (AOA) performed the gonioscopy which was confirmed by another author (SC) using a 3-mirror Goldmann goniolens (Volk Optical Inc, Mentor, Ohio, USA), and afterwards, a 4-mirror Zeiss goniolens (Carl Zeiss Meditec AG, Oberkochen, Germany) for indentation gonioscopy, in the undilated state under normal room illumination (approximately 240 lux), and darkness (approximately 0.1 lux) (the room was darkened for 5 minutes). Both conditions were previously measured with an illuminance meter [Minolta T10 Illuminance Meter, Konica Minolta Sensing Inc., Osaka, Japan]). The gonioscopic classification of the Glaucoma Service described in our previous paper was used ${ }^{(9)}$.

UBM exam was performed according to the technique described in a previous paper $^{(9)}$. Three clear and representative images from the temporal quadrant were selected for further analysis. Thirteen APAC eyes with neither topical nor systemic antiglaucomatous medications nor any laser or surgical procedure (Figure 1) were measured, under light and dark conditions for: 1 . the angle (the angle opening distance $500 \mu \mathrm{m}$ from the scleral spur - AOD500). AOD500 is the distance between the posterior corneal surface and the anterior iris surface measured on a line perpendicular to the trabecular meshwork, $500 \mu \mathrm{m}$ from the scleral spur); 2. the posterior chamber depth (PCD) taken from the posterior surface of the iris measured on a line extending from the corneal endothelium at $500 \mu \mathrm{m}$ from the scleral spur perpendicularly through the iris, to the anterior lens

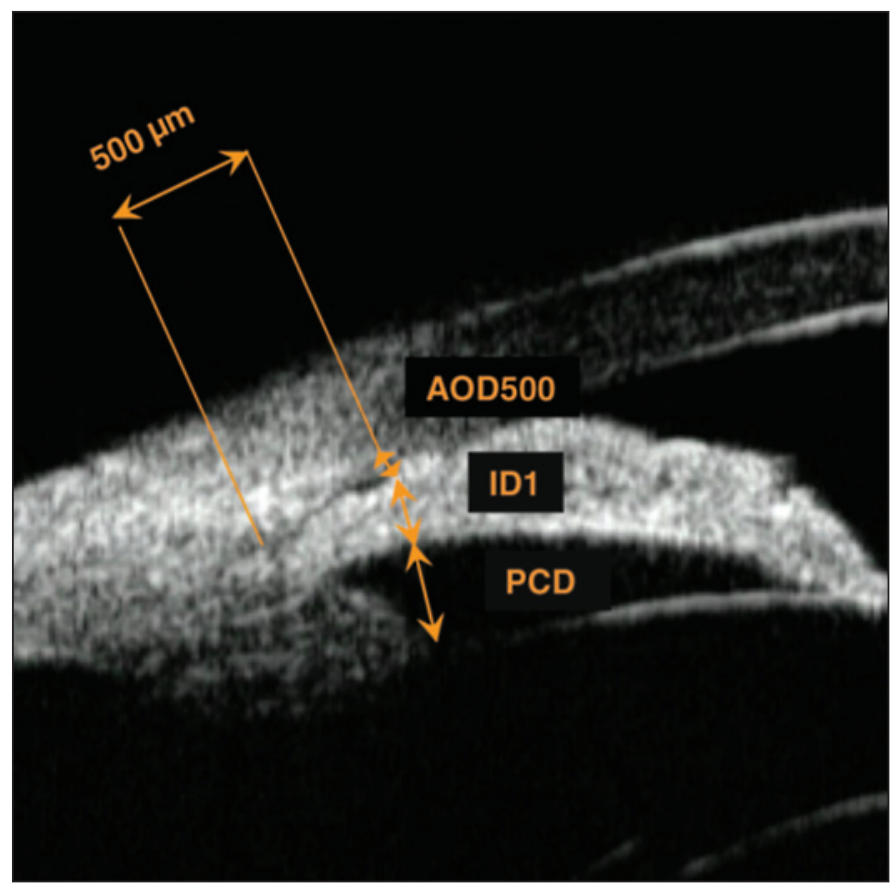

Figure 1 - AOD500 (angle opening distance $500 \mu \mathrm{m}$ from the scleral spur); ID1 (iris thickness); PCD (posterior chamber depth) 
capsule; 3 . the iris thickness (ID1) measured along the line extending from the corneal endothelium at $500 \mu \mathrm{m}$ from the scleral spur perpendicularly through the iris.

In 32 eyes, 16 with APAC and 16 with IPAC, UBM exam was done under light and dark conditions before and after LPI under equal conditions. The following items were measured: 1. Iris-lens contact distance (ILCD) (Figure 2), along the pigmented iris epithelium from the pupillary border to the point where the anterior lens surface leaves the iris; 2. Iris-lens angle (ILA) (Figure 3), the angle formed in arcdegree between two lines crossing the contact point between the iris and the lens, one touching the anterior lens capsule and the other touching the average third of the pigmented iris epithelium. One author (AOA) took all measurements on two different days to rule out inter and intra-observer variability ${ }^{(11)}$. All glaucoma drops were interrupted 48 hours before UBM exams.

16.0 SPSS was used for statistical analysis. Frequency histograms and the one-sample Kolmogorov-Smirnov and Wilcoxon tests were used. A $P$-value $<0.05$ was considered statistically significant.

\section{RESULTS}

Demographic, gonioscopic and clinical features of patients from the pilot study and APAC/IPAC patients are shown in table 1 . Table 2 demonstrates a significant decrease in the angle and a significant increase of the iris thickness from light to dark in the pilot study. The decrease in the angle corresponds to the increase in iris thickness. The PCD is slightly deeper under dark conditions but without significant difference. Table 3 shows the values of the UBM parameters be-

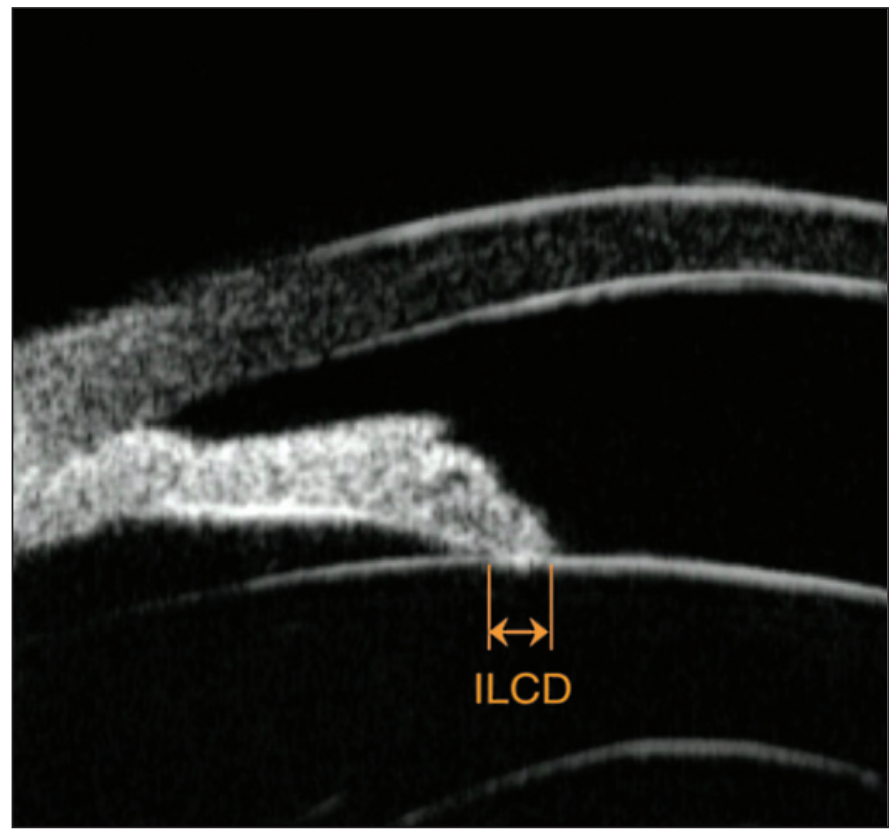

Figure 2 - ILCD (iris-lens contact distance) fore and after LPI, under light and dark conditions. Before LPI, the ILCD was greater under light conditions but without significant difference. Likewise, after LPI, the ILCD was also greater under light conditions but without significant difference. However, when we compared the ILCD under light conditions before and after LPI, a statistically significant difference was demonstrated $(P<0.001)$. Also, a statistically significant difference was found $(P<0.001)$ when comparing the ILCD under dark conditions before and after LPI. Conversely, in relation to ILA before LPI, the comparison between light and dark conditions demonstrated a lower statistically significant difference under light conditions $(P<0.005)$. After LPI, ILA values were lower under light conditions but without a significant difference $(P<0.085)$. No statistically significant difference was found when comparing the ACD before and after LPI under light and dark conditions (Table 3). Therefore, no change was demonstrated in the position of the iris-lens diaphragm (the central ACD was the same under light and dark conditions).

\section{DISCUSSION}

This study aimed to assess the UBM measurements in eyes with APAC or IPAC to find out new information about pupillary block. The patients, mainly leukodermic women, had an average age above 61.0 years and a hypermetropic spherical equivalent (Table 1). These are the most common features reported in literature regarding APAC or IPAC patients ${ }^{(12-15)}$.

For some authors, pupillary block possesses a great extension of ILCD (large iris-lens contact area) which was an aggravating factor ${ }^{(16-18)}$. However, this traditional concept was

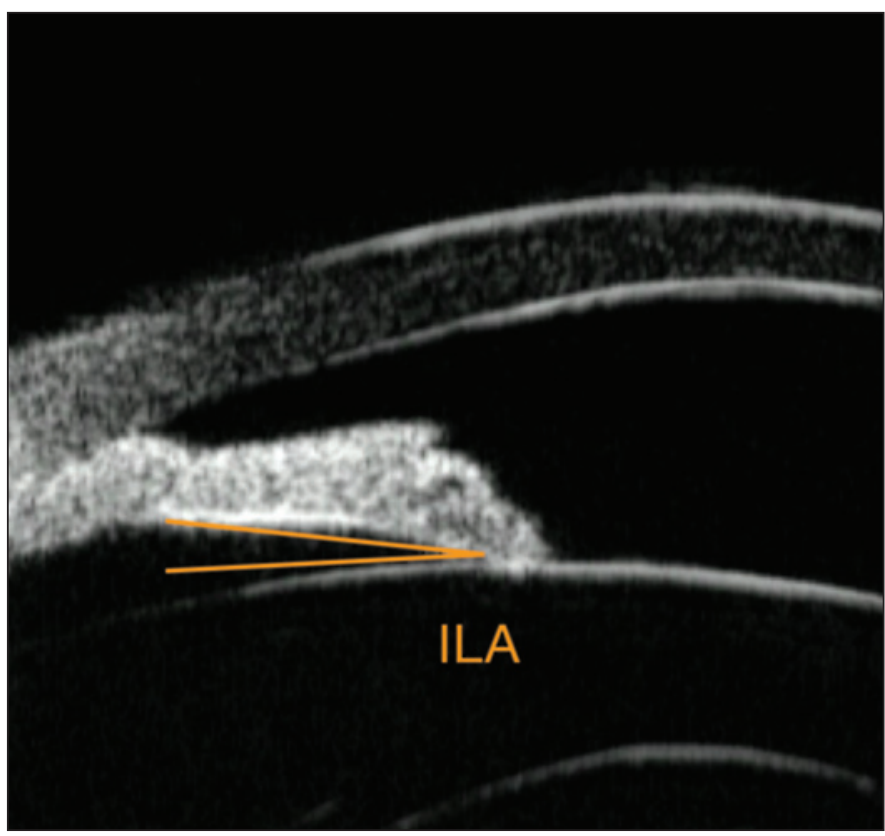

Figure 3 - ILA (iris-lens angle) 
based on imperfect observations due to the fact that the diagnostic device available at that time did not provide accurate ILCD measurements. One author believed that the ILCD was greater and the iris sphincter muscle exerted a posterior pressure against the lens in narrow angle glaucomatous eyes than in normal eyes ${ }^{(19)}$. Another author documented that the anterior iris convexity during pupillary block was because of a difference in pressure between the posterior and anterior chambers (greater pressure in the posterior chamber). He also observed a flattening of the iris and an increase in ILCD after LPI ${ }^{(19)}$. Some authors found an average ILCD of $1388 \pm 370$ microns in normal eyes ${ }^{(20)}$. Others studied 13 eyes with relative pupillary block and found an increase in ILCD after LPI ( $580 \pm 60$ microns vs. $1180 \pm 140$ microns $)^{(4)}$. Some papers reported that the ILCD was lower in patients with angle-closure and relative pupillary block than in normal patients ${ }^{(21)}$. Another paper showed that the ILCD of

\begin{tabular}{|c|c|c|}
\hline & $\begin{array}{l}\text { Pilot study } \\
n=13\end{array}$ & $\begin{array}{l}\text { APAC and IPAC } \\
n=16\end{array}$ \\
\hline Age (yrs) & $61.8 \pm 13.3$ & $62.9 \pm 12.1$ \\
\hline \multicolumn{3}{|l|}{ Gender } \\
\hline$\%$ male $(n)$ & 23.1 ( 3$)$ & $25.0(4)$ \\
\hline$\%$ female $(n)$ & $76.9(10)$ & $75.0(12)$ \\
\hline \multicolumn{3}{|l|}{ Race } \\
\hline \% leukodermic $(n)$ & 69.2 ( 9) & $81.2(13)$ \\
\hline$\%$ pheodermic $(n)$ & $23.1(3)$ & $12.5(2)$ \\
\hline$\%$ melanodermic $(\mathrm{n})$ & $7.7(1)$ & $6.3(1)$ \\
\hline \multicolumn{3}{|l|}{ Gonioscopy } \\
\hline \multicolumn{3}{|l|}{ Primary gaze position } \\
\hline$\%$ narrow open angle $(n)$ & $84.6(11)$ & $68.8(22)$ \\
\hline$\%$ closed angle $(n)$ & 15.4 ( 2) & $31.3(10)$ \\
\hline $\begin{array}{l}\text { Corrected visual acuity ( } \mathrm{n} \text { ) } \\
\text { (decimal scale) }\end{array}$ & $0.6 \pm 0.3(13)$ & $0.7 \pm 0.3(32)$ \\
\hline $\begin{array}{l}\text { Spherical equivalent }(\mathrm{n}) \\
\text { (diopters) }\end{array}$ & $+0.8 \pm 0.5(13)$ & $+0.6 \pm 0.5(32)$ \\
\hline \multicolumn{3}{|l|}{$C / D$} \\
\hline$\%<0.5(n)$ & $76.9(10)$ & 25.0 ( 8) \\
\hline$\% 0.5 \leq C / D \leq 0.6(n)$ & $7.7(1)$ & $31.3(10)$ \\
\hline$\% 0.6 \leq \mathrm{C} / \mathrm{D} \leq 0.9(\mathrm{n})$ & $15.4(2)$ & $43.7(14)$ \\
\hline \multicolumn{3}{|c|}{$\begin{array}{l}\text { Age, corrected visual acuity, spherical equivalent and C/D are average } \pm \\
\text { standard deviation values }\end{array}$} \\
\hline
\end{tabular}

fellow eyes of APAC decreased when the illumination changed from light to dark ${ }^{(9)}$.

This paper demonstrated an ILCD increase after LPI in APAC and IPAC eyes. The ILCD values (microns) were greater after LPI in light $(539 \pm 0.152$ vs $1.194 \pm 0.380)$ and dark conditions ( $0.464 \pm 0.131$ vs $0.936 \pm 0.269)$. In accordance with other papers ${ }^{(6,22)}$, a flattening of the iris after LPI was noted. The ILA (arcdegree) was reduced after LPI in light (15.38 \pm 3.90 vs. $9.81 \pm 4.06)$ and in dark conditions $(19.01 \pm 5.06$ vs. $11.26 \pm 5.83$ ) (Table 3). Thus, the LPI reduced the anterior iris curvature, and opened the angle due to the iris flattening. Normally, the iris is flattened because of the equalization of anterior and posterior chamber pressures ${ }^{(6)}$. No differences were found among the measurements from eyes with APAC and IPAC.

Three different and important forces involved in pupillary block have already been described as a mathematic model: 1 . force due to iris sphincter muscle's contraction (the lens position should be considered as well as the tonus of the autonomic nervous system); 2 . force due to the iris dilator muscle's contraction, and 3. force due to the stretching of iris tissue ${ }^{(23)}$.

Histological studies have proved that the iris dilator muscle fibers are much more developed and stronger in eyes with acute angle-closure than in normal eyes, and in the beginning of the acute attacks, stretching of the iris tissue plays an important role $^{(24)}$. In these eyes, the iris root is shorter and thicker ${ }^{(24)}$.

In this study, the LPI increased the ILCD and reduced the ILA (neutralizing the action the iris dilator muscle) $)^{(4)}$. According to Mapstone ${ }^{(23,25-26)}$, the forces described in the mathematic model ${ }^{(23)}$ would be the same, owing to the fact that the angle among them does not modify after the pupillary block resolution. In consequence, these forces have no importance in the genesis of pupillary block. For the same reasons, pilocarpine should not be used in APAC eyes. These data allow us to conclude that the impediment of aqueous humour flow from the posterior to the anterior chamber is not due to iris resistance in the pupil (pupillary block). Moreover, the iris does not have enough rigidity to cause the impediment of the aqueous humour flow to the anterior chamber during the crisis. Unfortunately to date, iris rigidity can not be measured but it is possible to assume that it is of minimal importance. On the other hand, anatomic and structural (angle) problems occur in eyes with APAC. In our opinion, an APAC is caused by an

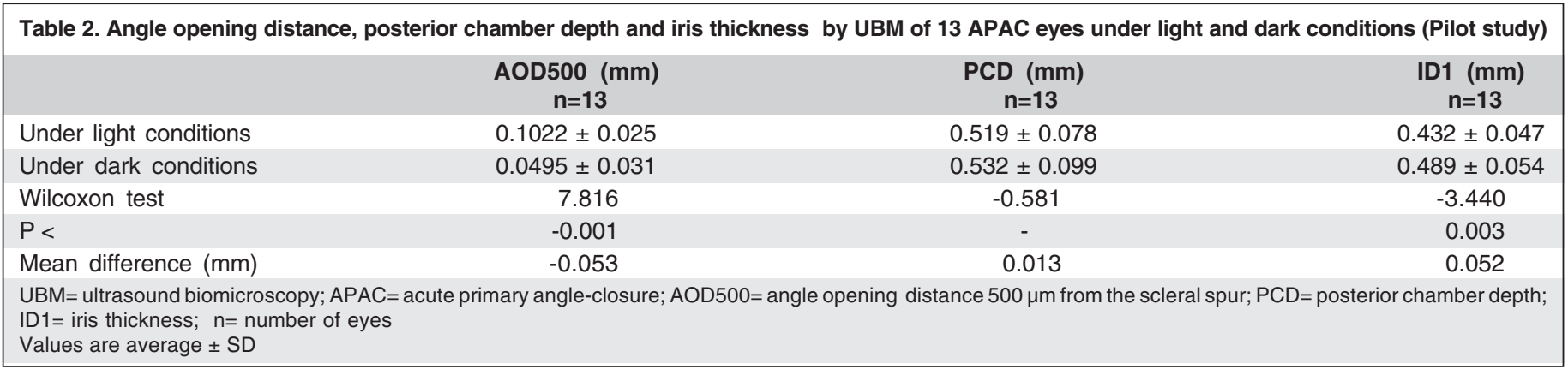




\begin{tabular}{|c|c|c|c|c|c|}
\hline & \multirow{2}{*}{$\begin{array}{c}\text { APAC and } \\
\text { IPAC Eyes } \\
n=32\end{array}$} & \multicolumn{4}{|c|}{ P-value } \\
\hline & & $\begin{array}{c}\text { Before vs } \\
\text { After LPI } \\
\text { LIGHT }\end{array}$ & $\begin{array}{l}\text { Before vs } \\
\text { After LPI } \\
\text { DARK }\end{array}$ & $\begin{array}{l}\text { LIGHT vs } \\
\text { DARK } \\
\text { Before LPI }\end{array}$ & $\begin{array}{l}\text { LIGHT vs } \\
\text { DARK } \\
\text { After LPI }\end{array}$ \\
\hline ILCD light before LPI (mm) & $0.539 \pm 0.152$ & ILCD & ILCD & ILCD & ILCD \\
\hline ILCD dark before LPI (mm) & $0.464 \pm 0.131$ & $<0.001^{a}$ & $<0.001^{a}$ & $0.070^{\mathrm{a}}$ & $<0.001^{a}$ \\
\hline ILCD light after LPI (mm) & $1.194 \pm 0.380$ & & & & \\
\hline ILCD dark after LPI (mm) & $0.936 \pm 0.269$ & & & & \\
\hline ILA light before LPI (arcdegree) & $15.380 \pm 3.900$ & ILA & ILA & ILA & ILA \\
\hline ILA dark before LPI (arcdegree) & $19.010 \pm 5.060$ & $<0.001^{a}$ & $<0.001^{\mathrm{a}}$ & $0.005^{a}$ & $0.085^{\mathrm{a}}$ \\
\hline ILA light after LPI (arcdegree) & $9.810 \pm 4.060$ & & & & \\
\hline ILA dark after LPI (arcdegree) & $11.260 \pm 5.830$ & & & & \\
\hline ACD light before LPI (mm) & $2.107 \pm 0.186$ & ACD & ACD & ACD & ACD \\
\hline ACD dark before LPI (mm) & $2.099 \pm 0.184$ & $0.344082^{a}$ & $0.135709^{a}$ & $0.90066^{a}$ & $0.657015^{a}$ \\
\hline ACD light after LPI (mm) & $2.101 \pm 0.172$ & & & & \\
\hline ACD dark after LPI (mm) & $2.106 \pm 0.195$ & & & & \\
\hline
\end{tabular}

imbalance of the autonomic nervous system (elevated sympathetic tonus) in sympathetic patients, which causes the contraction of the iris dilator muscle and, in turn, dilates the pupil in situations such as intense emotional disturbance, deficiency or absence of light and after the use of topic or systemic sympathicomimetic drugs. The pupil dilation caused by the contraction of the iris dilator muscle increases the middle-peripheral iris thickness (Table 2). A sector or annular iris' atrophy due to an ischemia of the iris dilator muscle can occur in some eyes with APAC depending on the strength and the time of duration of the iris dilator muscle's contraction.

Other relevant aspects to be considered are that after miosis and after LPI the force of the iris sphincter muscle is almost zero. In both situations, the ILCD is greater and therefore, contradicts the theory of pupillary block. In addition, the prone position dark-room provocative test can simulate the appositional angle closure in narrow angle eyes. It has already been shown that after this test, the angle and the anterior chamber depth (ACD) decrease in occludable angle eyes with and without LPI or under pilocapine ${ }^{(27)}$. The current consensus is that the use of pilocarpine and LPI are the two prophylactic and effective treatments for avoiding an APAC. This fact also constitutes another argument against the pupillary block. The iris dilator muscle's contraction is reduced after each of these treatments. By the same token, during the crisis, the force exerted by the iris dilator muscle causes a middle mydriasis in APAC eyes. This finding is in agreement with a minimum ILCD demonstrated by UBM under dark conditions (Figure 2). Therefore, in one occludable angle eye, the APAC is caused by peripheral iris thickening which blocks the angle and prevents aqueous humour drainage. As an example of the angle closing rather than pupillary block, 14 eyes of 11 patients with LPI were submitted to the prone position dark-room provocative test. Afterwards, the effect of $2 \%$ pilocarpine was assessed. It was noticed that with and without $2 \%$ pilocarpine the IOP showed an average increase from 13.86 to $18.07 \mathrm{mmHg}$ and $19.57 \mathrm{mmHg}$, respectively. This probably occurred due to angle block because the test can induce mydriasis and an anterior position of the lens. However, the $35.71 \%$ eyes having positive provocative test (IOP elevation $>8 \mathrm{mmHg}$ ) were transformed into negative after $2 \%$ pilocarpine, possibly due to less mydriasis than the test without pilocarpine ${ }^{(28)}$. We also did not find any significant statistical difference when comparing ACD before and after LPI under light and dark conditions (Table 3). This finding shows the force of the iris around the pupil has no importance in pupillary block.

It is known that pupillary block mechanism is the cause of acute angle closure in eyes which a posterior chamber phakic intraocular lens (PCPIOL) implantation is performed for correction of high myopia ${ }^{(29-30)}$. This only occurs in eyes without LPI prior to the PCPIOL implantation. Figure 4, an UBM image, demonstrates a true case of pupillary block (IOP was $45 \mathrm{mmHg} 20$ hours after PCPIOL implantation). It occurred in a patient without LPI due to a large extension of irisPCPIOL contact area which prevented the aqueous humor flow to the anterior chamber. In this case, the extension of the iris-PCPIOL contact area was $2.580 \mathrm{~mm}$ and the ILA was 16.03 (arcdegree). These values are much higher than those found in eyes with APAC after LPI under light conditions. An LPI resolved the pupillary block.

\section{CONCLUSION}

In our opinion, the most adequate denomination for pupillary block is "angle iris-block". The best option would be the establishment of normal angle values concerning iris sphincter and dilator muscle forces. This would provide real values thereby allowing the comparison of these forces. 


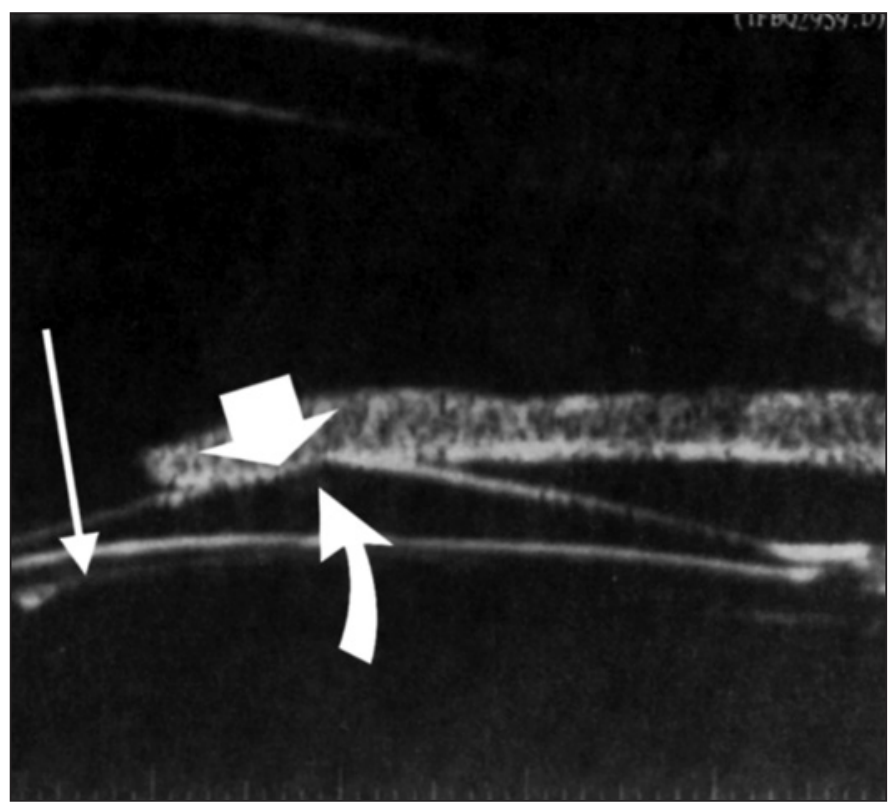

Figure 4 - UBM image showing a large extension of iris-PCPIOL contact area

In conclusion, we must emphasize that so far, UBM is a proper method to study APAC. Knowledge of the physical iris properties is important to establish its real role in the aqueous humour flow to the anterior chamber in the occurrence of a hypothetic pupillary block.

\section{RESUMO}

Objetivo: Investigar o mecanismo do bloqueio pupilar em olhos com fechamento angular primário agudo ou intermitente por meio da biomicroscopia ultrassônica. Métodos: Inicialmente, fez-se estudo piloto de 13 olhos com fechamento angular primário agudo sem medicação. Medimos pela biomicroscopia ultrassônica, no claro e no escuro, a amplitude do seio camerular, a profundidade da câmara posterior e a espessura da íris no quadrante temporal. Posteriormente, avaliamos pela biomicroscopia ultrassônica 32 olhos com fechamento angular primário agudo ou fechamento angular intermitente sem medicação, no claro e no escuro e antes e após iridectomia periférica. Medimos a distância de contato irido-cristaliniano e o ângulo irido-cristaliniano no quadrante temporal e a profundidade central da câmara anterior. Resultados: No estudo piloto, demonstrou-se com significância estatística redução da amplitude do seio camerular e aumento da espessura iriana quando se passou do claro para o escuro. Antes e após a iridectomia periférica, foram encontradas diferenças estatisticamente significativas na distância de contato irido-cristaliniano $(p<0,001)$ e no ângulo irido-cristaliniano $(p<0,001)$ ambos no claro e no escuro. Foram encontradas diferenças, estatisticamente significativas, no claro e no escuro, antes da iridectomia periférica no ângulo irido-cristaliniano $(p=0,005)$ e, após a iridectomia periférica na distância de contato irido-cristaliniano $(p<0,001)$.
Nenhuma diferença significativa ocorreu na profundidade central da câmara anterior. Conclusões: A diminuição da amplitude do seio camerular correspondeu somente ao aumento da espessura da íris. Após a iridectomia periférica, os olhos com fechamento angular primário agudo ou fechamento angular intermitente apresentaram, com significância estatística, aumento da distância de contato irido-cristaliniano e diminuição do ângulo irido-cristaliniano. A profundidade central da câmara anterior não se alterou. Esses achados contradizem a teoria de que o fechamento angular primário agudo ou fechamento angular intermitente ocorre por bloqueio pupilar.

Descritores: Glaucoma de ângulo fechado/ultrassonografia; Microscopia/métodos; Câmara anterior/ultrassonografia; Cristalino/fisiopatologia; Íris/fisiopatologia

\section{REFERENCES}

1. Barkan O. Narrow-angle glaucoma; pupillary block and the narrow-angle mechanism. Am J Ophthalmol. 1954;37(3):332-50.

2. Sugar HS. Newer concepts in classification of glaucomas. Am J Ophthalmol. 1949;32(3):425-33.

3. Lowe RF. Primary angle-closure glaucoma: a review of ocular biometry. Aust $\mathrm{N}$ Z J Ophthalmol. 1977;5(1):9-17.

4. Caronia RM, Liebmann JM, Stegman Z, Sokol J, Ritch R. Increase in iris-lens contact after laser iridotomy for pupillary block angle closure. Am J Ophthalmol. 1996;122(1):53-7.

5. Jin JC, Anderson DR. The effect of iridotomy on iris contour. Am J Ophthalmol. 1990;110(3):260-3.

6. Gazzard G, Friedman DS, Devereux JG, Chew P, Seah SK. A prospective ultrasound biomicroscopy evaluation of changes in anterior segment morphology after laser iridotomy in Asian eyes. Ophthalmology. 2003;110(3):630-8.

7. Pavlin CJ, Sherar MD, Foster FS. Subsurface ultrasound microscopic imaging of the intact eye. Ophthalmology. 1990;97(2):244-50.

8. Ritch R, Liebmann JM. Role of ultrasound biomicroscopy in the differentiation of block glaucomas. Curr Opin Ophthalmol. 1998;9(2):39-45.

9. Mérula RV, Cronemberger S, Diniz Filho A, Calixto N. New comparative ultrasound biomicroscopic findings between fellow eyes of acute angle closure and glaucomatous eyes with narrow angle. Arq Bras Oftalmol. 2008;71(6):7938. Comment in: Arq Bras Oftalmol. 2009;72(3):421-2.

10. Chylack LT Jr, Leske MC, McCarthy D, Khu P, Kashiwagi T, Sperduto R. Lens opacities classification System II (LOCS II). Arch Ophthalmol. 1989; 107(7):991-7. Comment in: Arch Ophthalmol. 1990;108(9):1209-10.

11. Tello C, Liebmann J, Potash SD, Cohen H, Ritch R. Measurement of ultrasound biomicroscopy images: intraobserver and interobserver reliability. Invest Ophthalmol Vis Sci. 1994;35(9):3549-52.

12. Pavlin CJ, Harasiewicz K, Foster FS. Ultrasound biomicroscopy of anterior segment structures in normal and glaucomatous eyes. Am J Ophthalmol. 1992; 113(4):381-9. Comment in: Am J Ophthalmol. 1992;114(4):516-7.

13. Lowe RF. Causes of shallow anterior chamber in primary angle-closure glaucoma. Ultrasonic biometry of normal and angle-closure glaucoma eyes. Am J Ophthalmol. 1969;67(1):87-93.

14. Ducasse A, Mathot E, Segal A, Favre F, Burette A. [Epidemiologic aspects of acute glaucoma crisis. Study carried out at the CHR of Reims]. Ophtalmologie. 1987;1(4):533-5. French.

15. Calixto N, Cronemberger S. Glaucoma simples x glaucoma agudo: estudo ecobiométrico. Arq Bras Oftalmol. 1986;49(1):1-8.

16. Lim MC, Lim LS, Gazzard G, Husain R, Chan YH, Seah SK, et al. Lens opacity, thickness, and position in subjects with acute primary angle closure. J Glaucoma. 2006;15(3):260-3.

17. Chandler P. Narrow-angle glaucoma. AMA Arch Ophthalmol. 1952;47(6):695-716.

18. Gorin G. Re-evaluation of gonioscopic findings in angle closure glaucoma. Static versus manipulative gonioscopy. Am J Ophthalmol. 1971;71(4):894-7.

19. Kondo T, Komurasaki Y, Takemura M. The effects of pilocarpine on pupil blocking force. Folia Ophthalmol Jpn. 1989;40:2721-5.

20. Anderson DR, Jin JC, Wright MM. The physiologic characteristics of relative pupillary block. Am J Ophthalmol. 1991;111(3):344-50. 
21. Pavlin CJ, Foster FS. Ultrasound biomicroscopy of the eye. New York: Springer-Verlag; 1995.

22. Walsh A, Pavlin CJ, Yamane R, Crema AS. Estudo do segmento anterior com biomicroscopia ultrassônica em bloqueio pupilar. Rev Bras Oftalmol. 1995; 54(6):405-15.

23. Mapstone R. Closed-angle glaucoma. Theoretical considerations. Br J Ophthalmol. 1974;58(1):36-40.

24. Lutjen E, Rohen JW. Histometric studies of the chamber angle region of the human eye in various age groups and glaucoma types. Albrecht Von Garefes Arch Exp Ophthalmol. 1968;176(1):1-12. German.

25. Mapstone R. The fellow eye. Br J Ophthalmol. 1981;65(6):410-3.

26. Mapstone R. Mechanics of pupil block. Br J Ophthalmol. 1968;52(1):19-25.
27. Pereira AC, Allemann N, Mello PA. Biomicroscopia ultrassônica do segmento anterior de olhos com seio camerular passível de oclusão. Arq Bras Oftalmol. 1999;62(3):298-305.

28. Malta RF. Prova de prono-posição em quarto escuro em olhos submetidos à iridectomia após glaucoma agudo primário. Efeito do colírio de pilocarpina a $2 \%$. Rev Bras Oftalmol. 1990;49(1):35-43.

29. Smallman DS, Probst L, Rafuse PE. Pupillary block glaucoma secondary to posterior chamber phakic intraocular lens implantation for high myopia. J Cataract Refract Surg. 2004;30(4):905-7.

30. Cronemberger S, Calixto N. Biomicroscopia ultrassônica. In: Dias JF, Almeida HG, Prata Júnior JÁ, editores. Glaucoma. $3^{\underline{a}}$ ed Rio de Janeiro: Cultura Médica; 2007. p.158-9

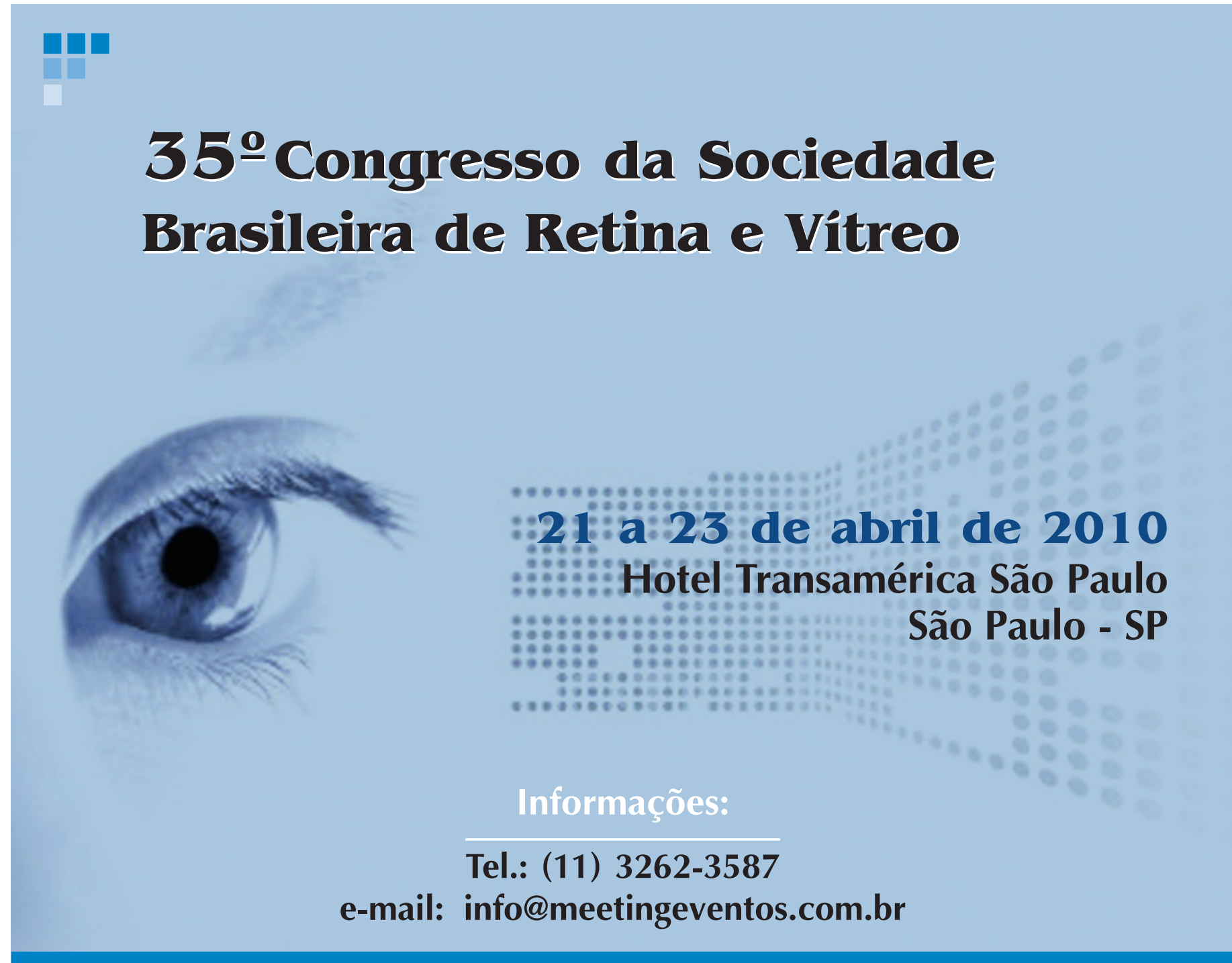

